\title{
Risk of gynecomastia and breast cancer associated with the use of 5-alpha reductase inhibitors for benign prostatic hyperplasia
}

\author{
This article was published in the following Dove Press journal: \\ Clinical Epidemiology \\ 10 February 2017 \\ Number of times this article has been viewed
}

\author{
Katrina Wilcox Hagberg' \\ Hozefa A Divan² \\ Shona C Fang ${ }^{2}$ \\ J Curtis Nickel ${ }^{3}$ \\ Susan S Jick' \\ 'Boston Collaborative Drug \\ Surveillance Program, Boston \\ University School of Public Health, \\ Lexington, ${ }^{2} \mathrm{New}$ England Research \\ Institutes, Inc., Watertown, MA, USA; \\ ${ }^{3}$ Kingston General Hospital, Queen's \\ University, Kingston, ON, Canada
}

Background: Clinical trial results suggest that 5-alpha reductase inhibitors (5ARIs) for the treatment of benign prostatic hyperplasia (BPH) may increase the risk of gynecomastia and male breast cancer, but epidemiological studies have been limited.

Patients and methods: We conducted a cohort study with nested case-control analyses using the UK Clinical Practice Research Datalink. We identified men diagnosed with BPH who were free from Klinefelter syndrome, prostate, genital or urinary cancer, prostatectomy or orchiectomy, or evidence of gynecomastia or breast cancer. Patients entered the cohort at age $\geq 40$ years and at least 3 years after the start of their electronic medical record. We classified exposure as $5 \mathrm{ARIs}$ (alone or in combination with alpha blockers [ABs]), AB only, or unexposed to 5 ARIs and ABs. Cases were men who had a first-time diagnosis of gynecomastia or breast cancer. Incidence rates and incidence rate ratios (IRRs) with $95 \%$ confidence intervals (CIs) in the gynecomastia analysis and crude and adjusted odds ratios (ORs) with 95\% CIs in both analyses were calculated.

Results: Compared to no exposure, gynecomastia risk was elevated for users of 5ARIs (alone or in combination with $\mathrm{ABs}$ ) in both the cohort (IRR=3.55, 95\% CI 3.05-4.14) and case-control analyses $(\mathrm{OR}=3.31,95 \% \mathrm{CI} 2.66-4.10)$, whereas the risk was null for users of $\mathrm{AB}$ only. The increased risk of gynecomastia with the use of 5ARIs persisted regardless of the number of prescriptions, exposure timing, and presence or absence of concomitant prescriptions for drugs known to be associated with gynecomastia. The risk was higher for dutasteride than for finasteride. 5ARI users did not have an increased risk of breast cancer compared to unexposed men $(\mathrm{OR}=1.52,95 \%$ CI $0.61-3.80)$.

Conclusion: In men with BPH, 5ARIs significantly increased the risk of gynecomastia, but not breast cancer, compared to $\mathrm{AB}$ use and no exposure.

Keywords: 5ARIs, benign prostatic hyperplasia, gynecomastia, male breast cancer

\section{Introduction}

Development of gynecomastia among men with benign prostatic hyperplasia (BPH) treated with 5-alpha reductase inhibitors (5ARIs; finasteride and dutasteride) has been reported in various case reports and studies. ${ }^{1-5}$ In addition, case reports and clinical trial results have suggested that treatment with 5ARIs may be associated with male breast cancer, ${ }^{6,7}$ a rare condition with a lifetime risk of $0.1 \%{ }^{8}$ An evidence review by the United Kingdom's (UK) national drug agency ${ }^{9}$ resulted in a finasteride drug warning label for breast cancer in the UK and Canada and initiation of an FDA safety probe for all 5ARIs in 2010. ${ }^{10}$
Correspondence: Katrina Wilcox Hagberg

Boston Collaborative Drug Surveillance Program, II Muzzey Street, Lexington,

MA 0242I, USA

Tel + I 78I 8626660

Fax +I 7818621680

Email khagberg@bu.edu 
To date, there have been no large observational studies of real-world data that evaluate the association between the use of 5ARIs and the risk of gynecomastia. In addition, clinical trials are neither large enough nor have long enough followup to identify male breast cancer cases in 5ARI users; thus, observational studies are an invaluable tool to assess this important association. We used the UK's Clinical Practice Research Datalink (CPRD), a large population-based general practice database, to conduct a cohort study with nested case-control analysis to examine the association between the use of 5ARIs and the risk of gynecomastia compared to unexposed, as well as to use of alpha blockers (ABs) for the treatment of BPH. We also conducted a case-control study to examine the association between the use of 5ARIs and the risk of male breast cancer.

\section{Patients and methods}

\section{Data source}

This study was conducted using the CPRD, a large, longitudinal, population-based electronic medical record database containing data on $\sim 10$ million people. ${ }^{11,12}$ Participating general practitioners (GPs) contribute data anonymously to the CPRD, including medical diagnoses, lifestyle details, details of hospital stays and specialist visits, and deaths, as well as details of all drugs prescribed. Data in the CPRD are collected prospectively in the absence of a study hypothesis, so there is no risk of recall bias. Validation studies have demonstrated the high accuracy of clinical diagnoses. ${ }^{13}$

\section{Study population of $5 A R I$ and $A B$ users}

We identified all men in the CPRD from 1992 through 2014 who had a diagnosis of BPH or prostatism and who received a prescription for either a 5ARI (finasteride or dustasteride) and/or an AB (alfuzosin, doxadosin, indoramin, prazosin, tamsulosin, and terazosin). ABs, an alternative pharmaceutical treatment of BPH, were included as an active comparator. Men with a diagnosis of Klinefelter syndrome at any time were excluded. Men with prostate, genital, or urinary cancer, or prostatectomy or orchiectomy prior to the first $5 \mathrm{ARI}$ or AB prescription were also excluded from the study population.

\section{Gynecomastia study}

From the study population, we identified the cohort of men to be followed for gynecomastia. Men entered the cohort at age $\geq 40$ years and at least 3 years after electronic medical record start date (to allow for adequate capture of covariates and prescribing history). To be included, men were required to have no 5ARI or $\mathrm{AB}$ prescriptions (to restrict to new users), no previous gynecomastia diagnoses, and no diagnosis of pituitary or adrenal cancer, liver disease, renal failure, or hypogonadism (risk factors for gynecomastia) prior to cohort entry date. Additionally, men with a breast cancer diagnosis at any time were excluded.

For each patient, we calculated person-days of exposure as follows: duration of filled use of 5ARIs or ABs was calculated as the quantity of pills divided by the number of pills per day. Exposure was classified as 5ARIs (alone or in combination with ABs), ABs only, or unexposed to either 5ARIs or ABs. For each exposure, we also calculated person-days of exposure to "current" (filled use plus 30 days), "recent" (days 31-90 after the end of current use), and "past use" (days 91-150 after the end of current use) and "nonexposed" (number of days between cohort entry and censor where no 5ARI and/or AB prescriptions were received or the period after the end of past use). The censor date was defined as the first of the following: end of record, death, or date of diagnosis of prostate, urinary, genital, pituitary, or adrenal cancers, prostatectomy, orchidectomy, liver disease, renal failure, hypogonadism, or the date the man was diagnosed with gynecomastia (index date). Gynecomastia cases were men with a first diagnosis of gynecomastia recorded during follow-up. We calculated incidence rates (IRs) and incidence rate ratios (IRRs) with 95\% confidence intervals (CIs) for each exposure, adjusted by age, calendar year, and prescriptions for other drugs known to be associated with gynecomastia development (e.g., cimetidine, ketoconazole, hormone replacement, goserelin, and metoclopramide).

\section{Gynecomastia nested case-control analysis}

Using the gynecomastia cases identified in the cohort study, we conducted a nested case-control analysis to carefully control for age, calendar time, and gynecomastia risk factors. We further excluded cases with cancer diagnosed within 2 years before the index date $(n=28)$ because some cancer treatments (e.g., chemotherapy and radiation) are associated with gynecomastia development. From the study cohort, we matched up to four controls to each gynecomastia case on year of birth ( \pm 2 years), general practice attended, index date (same index date as the matched case), and start year in the CPRD ( \pm 2 years). Controls met all the same requirements as cases and could not have a gynecomastia diagnosis before the index date.

Covariates of interest included known or suspected gynecomastia risk factors, including age, calendar time, body 
mass index (BMI: <18.5, 18.5-24.9, 25-29.9, $\geq 30 \mathrm{~kg} / \mathrm{m}^{2}$, and unknown), smoking (never, smoker, ex-smoker, and unknown), hypertension, cardiovascular disease (CVD), cancer, alcohol-related disorders, and prescription drugs known to be associated with the development of gynecomastia (e.g., cimetidine, ketoconazole, hormone replacement, goserelin, and metoclopramide). We calculated crude and adjusted odds ratios (ORs) with 95\% CIs. We assessed the potential for gynecomastia case misclassification in sensitivity analyses restricted to the cases with referral or treatment codes that supported the diagnosis of gynecomastia and their matched controls.

\section{Male breast cancer study}

We conducted a nested case-control study of all breast cancer cases identified in the study population of $5 \mathrm{ARI}$ and $\mathrm{AB}$ users with no previous cancer diagnosis (except nonmelanoma skin cancer). The index date was the first breast cancer diagnosis date minus 1 year (to account for an induction period). Cases were required to have at least 2 years of recorded information in the CPRD before the index date. We matched up to 10 controls without a breast cancer diagnosis to each breast cancer case on year of birth ( \pm 2 years), general practice attended, index date (same index date as matched case), and start year in the CPRD ( \pm 2 years). Controls were subject to the same criteria as cases.

A patient was considered exposed to 5ARIs (alone or in combination with $\mathrm{ABs}$ ) or $\mathrm{ABs}$ only if they received two or more prescriptions for 5ARIs or ABs before the index date. All others were nonexposed. We also evaluated timing of exposure (current, recent, and past) and number of prescriptions as a proxy for duration of use.

Covariates of interest included BMI, smoking status, prostate surgeries (i.e., transurethral resection of prostate), and gynecomastia diagnosed 2 years before the index date. We calculated crude ORs and ORs adjusted for prostate surgery and gynecomastia and 95\% CIs using conditional logistic regression to estimate the risk of breast cancer in users of 5ARIs or ABs compared to nonexposed. In a sensitivity analysis to evaluate the latency period, we used an index date of 2 years prior to breast cancer diagnosis.

All statistical analyses were conducted using SAS statistical software version 9.3 (SAS Institute, Cary, NC, USA). The protocols for this study were reviewed and approved by the Independent Scientific Advisory Committee of the CPRD (protocol numbers 15_086 and 15_124). This was an observational study using anonymized electronic medical record data. Written consent from patients was not required due to the nature of this study.

\section{Results \\ Gynecomastia analysis}

We identified 94,701 men who were eligible for inclusion in the gynecomastia cohort, the majority of which were nonexposed at cohort entry (Table 1). The IR of gynecomastia was 40.2 per 10,000 person-years (PY) (95\% CI 35.6-45.2) for 5ARI users, 12.2 per 10,000 PY (95\% CI 10.7-13.9) for users of $\mathrm{AB}$ only, and 7.2 per 10,000 PY (95\% CI 6.7-7.8) for unexposed men. The IRRs, compared to unexposed men

Table I Characteristics of gynecomastia cohort $(\mathrm{N}=94,70$ I)

\begin{tabular}{|c|c|}
\hline Characteristics & n (\%) \\
\hline \multicolumn{2}{|l|}{ Age (years) at cohort entry } \\
\hline $40-49$ & $16,160(17.1)$ \\
\hline $50-59$ & $28,75 I(30.4)$ \\
\hline $60-69$ & $30,626(32.3)$ \\
\hline 70-79 & $16,109(17.0)$ \\
\hline $80-89$ & $2922(3.1)$ \\
\hline$\geq 90$ & $133(0.1)$ \\
\hline \multicolumn{2}{|l|}{ Year of cohort entry } \\
\hline$<1995$ & $46,056(48.6)$ \\
\hline $1995-1999$ & $26,533(28.0)$ \\
\hline 2000-2004 & 13,957 (14.7) \\
\hline $2005-2009$ & $6705(7.1)$ \\
\hline$\geq 2010$ & $1450(1.5)$ \\
\hline \multicolumn{2}{|l|}{ Length of follow-up (years) } \\
\hline$<1$ & $877(0.9)$ \\
\hline $1-4$ & $9947(10.5)$ \\
\hline $5-9$ & $21,383(22.6)$ \\
\hline $10-14$ & $28,417(30.0)$ \\
\hline$\geq 15$ & $34,077(36.0)$ \\
\hline \multicolumn{2}{|l|}{ BMl at cohort entry $\left(\mathrm{kg} / \mathrm{m}^{2}\right)$} \\
\hline$<18.5$ & $669(0.7)$ \\
\hline $18.5-24.9$ & $30,606(32.3)$ \\
\hline $25-29.9$ & $41,777(44.1)$ \\
\hline$\geq 30$ & $|5,66|(16.5)$ \\
\hline Unknown & $5988(6.3)$ \\
\hline \multicolumn{2}{|l|}{ Smoking status at cohort entry } \\
\hline Nonsmoker & $36,844(38.9)$ \\
\hline Smoker & $15,968(16.9)$ \\
\hline Ex-smoker & $15,556(16.4)$ \\
\hline Unknown & $26,333(27.8)$ \\
\hline \multicolumn{2}{|l|}{ Comorbidities at cohort entry } \\
\hline Hypertension & I7,658 (I8.7) \\
\hline Diabetes & 4680 (4.9) \\
\hline Hyperlipidemia & $6248(6.6)$ \\
\hline Cardiovascular disease & $14,734(15.6)$ \\
\hline Benign prostatic hyperplasia & $5187(5.5)$ \\
\hline Cancer & $1443(1.5)$ \\
\hline Hyperthyroid & $403(0.4)$ \\
\hline \multicolumn{2}{|l|}{ Exposure on cohort entry date } \\
\hline Unexposed & $94,688(99.9)$ \\
\hline $5 A R I$ & $\mathrm{I}(0.0)$ \\
\hline$A B$ & $12(0.1)$ \\
\hline
\end{tabular}

Note: ${ }^{\text {aC }}$ Cohort entry was defined as age $\geq 40$ years and 3 years after the start of the patient's electronic record.

Abbreviations: $B M I$, body mass index; $5 A R I$, 5-alpha reductase inhibitor; $A B$, alpha blocker. 
and adjusted for age, calendar year, and use of drugs associated with gynecomastia, were 3.55 (95\% CI 3.05-4.14) for users of 5ARIs and 1.15 (95\% CI 0.98-1.34) for users of $\mathrm{AB}$ only (Table 2).

Table 3 presents the characteristics of cases and matched controls. The adjusted OR for gynecomastia was threefold higher for users of 5ARIs (alone or in combination with ABs) compared to nonexposed men (Table 4). The risk remained elevated regardless of the number of 5ARI prescriptions received or exposure timing. The risk of gynecomastia was similar for men who were prescribed 5ARIs alone (adjusted $\mathrm{OR}=3.29,95 \%$ CI $2.53-4.26$ ) and for men who were prescribed 5ARIs in combination with ABs (adjusted $\mathrm{OR}=3.33$, 95\% CI 2.45-4.45). The risk was higher for dutasteride (adjusted OR=5.40, 95\% CI 3.64-8.00) than for finasteride (adjusted OR=2.92, 95\% CI 2.31-3.68). In contrast, there was no elevation in risk of $\mathrm{AB}$ only users compared to nonexposed (adjusted OR=1.01, 95\% CI 0.82-1.23), and the results remained null regardless of the number of $\mathrm{AB}$ prescriptions or exposure timing (Table 4).

We assessed effect modification by stratifying on presence or absence of concomitant prescriptions for drugs known to be associated with gynecomastia within 60 days of the index date (Table 5). The reference in this analysis was unexposed men who did not have any prescriptions for drugs known to be associated with gynecomastia. The elevation in risk with 5ARI use was present with or without these concomitant prescriptions (with: adjusted OR $=5.32,95 \%$ CI 4.00-7.08 and without: adjusted $\mathrm{OR}=5.85,95 \% \mathrm{CI} 4.36-7.84$ ). For users of ABs only, the risk of gynecomastia was elevated only in patients with these concomitant prescriptions (adjusted $\mathrm{OR}=2.66,95 \%$ CI 2.04-3.47), while it was not elevated in AB-only users with no such prescriptions (adjusted $\mathrm{OR}=1.07$, 95\% CI 0.80-1.43).

The results for the sensitivity analysis to assess case misclassification, restricted to 649 (56.8\%) cases with clinical codes consistent with diagnosis or treatment of gynecomastia and their matched controls, were not materially different from the main analysis.

\section{Male breast cancer analysis}

We identified 48 male breast cancer cases and 478 matched controls. Male breast cancer cases were more likely than controls to have had surgery on their prostate or a gynecomastia diagnosis $>2$ years before the index date (Table 6 ). There was no association between the use of $5 \mathrm{ARIs}$ or $\mathrm{ABs}$ and the risk of breast cancer: The adjusted OR for breast cancer with the use of 5ARIs (alone or in combination with ABs) was 1.52 (95\% CI 0.61-3.80) compared to nonexposed, while the

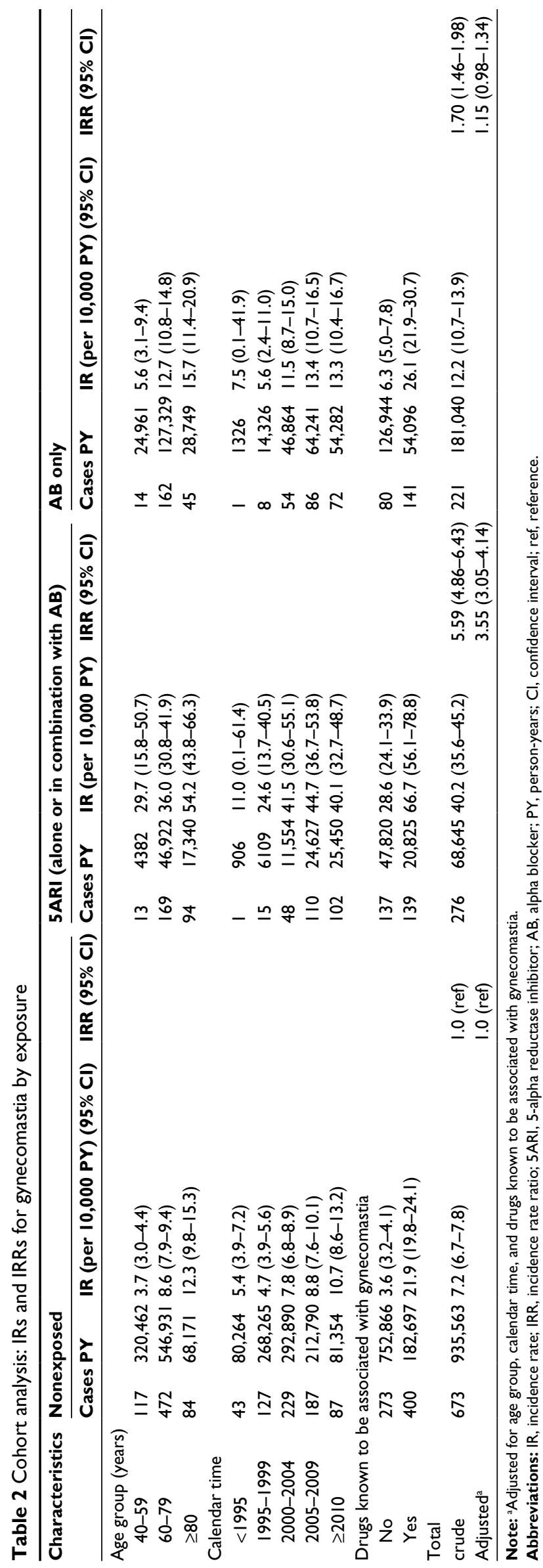


Table 3 Gynecomastia-nested characteristics by case/control status

\begin{tabular}{|c|c|c|c|}
\hline Characteristics & $\begin{array}{l}\text { Gynecomastia } \\
\text { cases, } n=1 \text { I 42, } \\
n(\%)\end{array}$ & $\begin{array}{l}\text { Controls, } \\
n=4 \text { I 64, } \\
n(\%)\end{array}$ & $\begin{array}{l}\text { Univariate OR } \\
(95 \% \mathrm{Cl})\end{array}$ \\
\hline \multicolumn{4}{|c|}{ Age (years) at index date } \\
\hline $40-49$ & $17(1.5)$ & $67(1.6)$ & a \\
\hline $50-59$ & $124(10.9)$ & $479(11.5)$ & a \\
\hline $60-69$ & $386(33.8)$ & $1423(34.2)$ & a \\
\hline 70-79 & $397(34.8)$ & $1457(35.0)$ & a \\
\hline $80-89$ & $203(17.8)$ & $698(16.8)$ & a \\
\hline$\geq 90$ & $15(1.3)$ & $40(1.0)$ & a \\
\hline Mean \pm SD & $70.5 \pm 9.4$ & $70.2 \pm 9.4$ & a \\
\hline \multicolumn{4}{|l|}{ Index year } \\
\hline$<1995$ & $45(3.9)$ & $172(4.1)$ & a \\
\hline $1995-1999$ & $147(12.9)$ & $546(13.1)$ & a \\
\hline $2000-2004$ & $324(28.4)$ & $1209(29.0)$ & a \\
\hline $2005-2009$ & $374(32.8)$ & $1358(32.6)$ & a \\
\hline$\geq 2010$ & $252(22.1)$ & $879(21.1)$ & a \\
\hline \multicolumn{4}{|c|}{ Length of record before index date (years) } \\
\hline Mean \pm SD & $12.6 \pm 5.4$ & $12.4 \pm 5.4$ & a \\
\hline \multicolumn{4}{|l|}{ BMI $\left(\mathrm{kg} / \mathrm{m}^{2}\right)$} \\
\hline$<18.5$ & $16(1.4)$ & $42(1.0)$ & $1.29(0.7 I-2.32)$ \\
\hline $18.5-24.9$ & $374(32.8)$ & $1263(30.3)$ & 1.0 (ref) \\
\hline $25-29.9$ & $452(39.6)$ & $1843(44.3)$ & $0.84(0.72-0.98)$ \\
\hline$\geq 30$ & 261 (22.9) & $812(19.5)$ & $1.10(0.92-1.33)$ \\
\hline Unknown & $39(3.4)$ & $204(4.9)$ & $0.65(0.45-0.94)$ \\
\hline Mean \pm SD & $27.2 \pm 5.2$ & $27.0 \pm 4.3$ & \\
\hline \multicolumn{4}{|l|}{ Smoking status } \\
\hline Nonsmoker & $438(38.4)$ & 1654 (39.7) & 1.0 (ref) \\
\hline Smoker & $108(9.5)$ & $522(12.4)$ & $0.78(0.62-0.99)$ \\
\hline Ex-smoker & $540(47.3)$ & $1740(4 \mid .8)$ & $1.18(1.02-1.38)$ \\
\hline Unknown & $56(4.9)$ & $248(6.0)$ & $0.82(0.58-1.15)$ \\
\hline \multicolumn{4}{|l|}{ Comorbidities } \\
\hline Hypertension & $464(40.6)$ & $1572(37.8)$ & $1.13(0.98-1.29)$ \\
\hline Diabetes & $136(11.9)$ & 481 (II.6) & $1.03(0.84-1.26)$ \\
\hline Hyperlipidemia & $269(23.6)$ & $772(18.5)$ & $1.38(1.17-1.63)$ \\
\hline $\begin{array}{l}\text { Cardiovascular } \\
\text { disease }\end{array}$ & $517(45.3)$ & $1386(33.3)$ & 1.71 (1.49-1.97) \\
\hline $\begin{array}{l}\text { Benign prostatic } \\
\text { hyperplasia }\end{array}$ & $555(48.6)$ & 1785 (42.9) & $1.27(1.10-1.46)$ \\
\hline Orchitis & $66(5.8)$ & $214(5.1)$ & $1.15(0.86-1.53)$ \\
\hline $\begin{array}{l}\text { Alcohol-related } \\
\text { disorders }\end{array}$ & $56(4.9)$ & $159(3.8)$ & $1.32(0.96-1.81)$ \\
\hline $\begin{array}{l}\text { Cancer }>2 \text { years } \\
\text { before index date }\end{array}$ & $55(4.8)$ & $|3|(3.2)$ & $1.56(1.12-2.16)$ \\
\hline Hyperthyroid & $10(0.9)$ & $29(0.7)$ & $1.26(0.6 I-2.62)$ \\
\hline $\begin{array}{l}\text { Drugs associated } \\
\text { with gynecomastia } \\
\text { prescribed within } \\
60 \text { days of index } \\
\text { date }\end{array}$ & $658(57.6)$ & $1567(37.6)$ & $2.35(2.05-2.70)$ \\
\hline
\end{tabular}

Note: a Matching variable.

Abbreviations: OR, odds ratio; $\mathrm{Cl}$, confidence interval; $\mathrm{BMI}$, body mass index; ref, reference.

adjusted OR for use of ABs was 0.71 (95\% CI 0.31-1.62; Table 7). There were too few cases to estimate the risk of breast cancer for users of 5ARIs alone or to assess differences in risk by type of 5ARI prescribed. There was no material difference in the results when we moved the index date to the breast cancer diagnosis date minus 2 years.

\section{Discussion}

We observed a greater than threefold elevation in risk of gynecomastia for users of 5ARIs (alone or in combination with $A B s$ ) in comparison to unexposed men, whereas there was no elevation of risk for men using ABs for the treatment of BPH. The increase in risk of gynecomastia with the use of 5ARIs was present regardless of number of prescriptions, timing of use, and presence of concomitant prescriptions for drugs known to be associated with gynecomastia. Among 5ARI users, the risk of gynecomastia was higher for users of dutasteride than finasteride. In contrast, our results suggest that the use of 5ARIs do not increase the risk of breast cancer in comparison to nonexposed men.

Like the results of our study, prior studies have reported increases in risk of gynecomastia with the use of 5ARIs, ranging from $\sim 1.6$ to 3.1 . The PCPT Trial, ${ }^{14}$ a 7 -year prostate cancer prevention study, reported gynecomastia occurrence of $4.5 \%$ in finasteride-treated compared to $2.8 \%$ of placebotreated patients $(p<0.001$; crude risk ratio $\sim 1.6)$. Similarly, the REDUCE Trial, ${ }^{15}$ a 4-year prostate cancer prevention study, reported that gynecomastia occurred in $1.9 \%$ of dutasteridetreated compared to $1 \%$ of placebo-treated patients $(p=0.002$; crude risk ratio 1.9). The ARIA/ARIB trial, ${ }^{16}$ a study of men with BPH, reported an elevated risk of gynecomastia of 3.11 (95\% CI 1.78-5.45) for dutasteride compared to placebo. In a retrospective analysis ${ }^{17}$ of 378 men with BPH treated with 5ARIs, breast tenderness or enlargement events were reported more frequently among dutasteride (3.3\%) compared to $1.5 \%$ of finasteride-treated men (risk ratio 2.2). Finally, in a pooled analysis of published randomized, placebo-controlled clinical trials the overall rate of gynecomastia was $2.8 \%$ with 5ARIs compared to $1.6 \%$ for placebo (risk ratio $\sim 1.8$ ). ${ }^{18}$

In the few clinical trials that reported breast cancer development, the incidence of breast cancer was $<0.3 \%$ of men taking 5ARIs. ${ }^{18}$ Results of previously published observational studies on breast cancer and 5ARI use have been null. Results of a case-control study of 339 cases using the US IMS LifeLink Health Plan claims database from 2001 to $2009^{19}$ indicated no increase in the risk of breast cancer associated with 5ARI use (OR=0.70, 95\% CI 0.34-1.45). Results from a case-control study ${ }^{20}$ using the CPRD ( $\mathrm{n}=398$ cases) with a 6-month latency period and adjusting for history of lymphoma, gynecomastia, testicular cancer, and treatment 
Table 4 Case-control analysis: 5ARI and AB exposure among gynecomastia cases and matched controls

\begin{tabular}{|c|c|c|c|c|}
\hline Exposure & $\begin{array}{l}\text { Gynecomastia } \\
\text { cases, } n=1 \mid 42, n \text { (\%) }\end{array}$ & $\begin{array}{l}\text { Controls, } \\
n=4164, n \text { (\%) }\end{array}$ & Crude OR $(95 \% \mathrm{Cl})$ & Adj OR $^{\mathrm{a}}(95 \% \mathrm{Cl})$ \\
\hline Nonexposed & $661(57.9)$ & $2855(68.6)$ & 1.0 (ref) & 1.0 (ref) \\
\hline $5 A R I$ (only or in combination with $A B$ ) & $272(23.8)$ & $394(9.5)$ & $3.26(2.69-3.97)$ & $3.31(2.66-4.10)$ \\
\hline Finasteride & $198(17.3)$ & $322(7.7)$ & $2.87(2.32-3.54)$ & $2.92(2.31-3.68)$ \\
\hline Dutasteride & $74(6.5)$ & $72(1.7)$ & $5.42(3.74-7.85)$ & $5.40(3.64-8.00)$ \\
\hline$A B$ only & $209(18.3)$ & $915(22.0)$ & $1.04(0.87-1.25)$ & $1.01(0.82-1.23)$ \\
\hline \multicolumn{5}{|l|}{ Number of prescriptions } \\
\hline Nonexposed & $661(57.9)$ & $2855(68.6)$ & I.0 (ref) & I.0 (ref) \\
\hline \multicolumn{5}{|l|}{$5 A R I$ (only or in combination with $A B$ ) } \\
\hline I prescription & $8(0.7)$ & $14(0.3)$ & $2.72(1.12-6.60)$ & $2.33(0.94-5.79)$ \\
\hline 2-9 prescriptions & $82(7.2)$ & $92(2.2)$ & $4.14(3.01-5.69)$ & $4.27(3.03-6.01)$ \\
\hline $10-19$ prescriptions & $73(6.4)$ & $90(2.2)$ & $3.72(2.66-5.21)$ & $3.82(2.67-5.47)$ \\
\hline 20-29 prescriptions & $46(4.0)$ & $48(1.2)$ & $4.44(2.89-6.82)$ & $4.60(2.92-7.26)$ \\
\hline$\geq 30$ prescriptions & $63(5.5)$ & $150(3.6)$ & $1.95(I .4 I-2.70)$ & $1.89(1.33-2.69)$ \\
\hline \multicolumn{5}{|l|}{$A B$ only } \\
\hline I prescription & $9(0.8)$ & $47(\mathrm{I} . \mathrm{l})$ & $0.91(0.44-1.88)$ & $0.93(0.45-1.95)$ \\
\hline 2-9 prescriptions & $54(4.7)$ & $192(4.6)$ & $1.23(0.89-1.69)$ & $1.20(0.86-1.68)$ \\
\hline $10-19$ prescriptions & $40(3.5)$ & $175(4.2)$ & $1.04(0.73-1.50)$ & $\mathrm{I} .04(0.7 \mathrm{I}-\mathrm{I} .53)$ \\
\hline 20-29 prescriptions & $39(3.4)$ & $118(2.8)$ & $1.50(1.03-2.19)$ & $1.37(0.93-2.03)$ \\
\hline$\geq 30$ prescriptions & $67(5.9)$ & $383(9.2)$ & $0.80(0.6 \mathrm{I}-1.07)$ & $0.77(0.57-1.03)$ \\
\hline \multicolumn{5}{|l|}{ Exposure timing } \\
\hline Nonexposed & $661(57.9)$ & $2855(68.6)$ & $\mathrm{I} .0$ (ref) & 1.0 (ref) \\
\hline \multicolumn{5}{|l|}{$5 \mathrm{ARI}$ (only or in combination with $\mathrm{AB}$ ) } \\
\hline Current & $240(21.0)$ & $368(8.8)$ & $3.09(2.53-3.79)$ & $3.14(2.51-3.92)$ \\
\hline Recent & $23(2.0)$ & $19(0.5)$ & $5.49(2.93-10.30)$ & $6.64(3.39-12.98)$ \\
\hline Past & $9(0.8)$ & $7(0.2)$ & $5.12(1.89-13.88)$ & $3.83(1.34-10.91)$ \\
\hline \multicolumn{5}{|l|}{$A B$ only } \\
\hline Current & $185(16.2)$ & $796(19.1)$ & $1.06(0.87-1.28)$ & $1.02(0.83-1.26)$ \\
\hline Recent & II (I.0) & $79(1.9)$ & $0.62(0.33-1.19)$ & $0.59(0.30-1.16)$ \\
\hline Past & $13(1.1)$ & $40(1.0)$ & $\mathrm{I} .53(0.8 \mathrm{I}-2.89)$ & I.45 $(0.75-2.78)$ \\
\hline
\end{tabular}

Notes: ${ }^{a}$ Adjusted for body mass index, smoking status, hypertension, hyperlipidemia, cardiovascular disease, cancer, alcohol-related disorders, benign prostatic hyperplasia, and drugs known to be associated with gynecomastia prescribed within 60 days prior to the index date, conditional on the matching factors.

Abbreviations: 5ARI, 5-alpha reductase inhibitor; $\mathrm{AB}$, alpha blocker; adj OR, adjusted odds ratio; ref, reference; $\mathrm{Cl}$, confidence interval.

Table 5 Gynecomastia case-control analysis: 5ARI and AB exposure among gynecomastia cases and matched controls, stratified by use of drugs known to be associated with gynecomastia

\begin{tabular}{|c|c|c|c|c|}
\hline Exposure & Gynecomastia cases, n= | | 42, n (\%) & Controls, $n=4 \mid 64, n$ (\%) & Crude OR $(95 \% \mathrm{Cl})$ & $\operatorname{Adj~OR}^{a}(95 \% \mathrm{Cl})$ \\
\hline \multicolumn{5}{|l|}{ Nonexposed } \\
\hline No gyn drugs & $269(23.6)$ & $1849(44.4)$ & I.0 (ref) & I.0 (ref) \\
\hline Gyn drugs & $392(34.3)$ & $1006(24.2)$ & $2.93(2.44-3.52)$ & $2.79(2.32-3.36)$ \\
\hline \multicolumn{5}{|c|}{$5 A R I$ (only or in combination with $A B$ ) } \\
\hline No gyn drugs & $136(11.9)$ & $212(5.1)$ & $5.35(4.08-7.01)$ & $5.32(4.00-7.08)$ \\
\hline Gyn drugs & $136(11.9)$ & $182(4.4)$ & $6.31(4.77-8.35)$ & $5.85(4.36-7.84)$ \\
\hline \multicolumn{5}{|l|}{$A B$ only } \\
\hline No gyn drugs & $79(6.9)$ & $536(12.9)$ & $1.09(0.82-1.44)$ & $1.07(0.80-1.43)$ \\
\hline Gyn drugs & $130(11.4)$ & $379(9.1)$ & $2.85(2.21-3.68)$ & $2.66(2.04-3.47)$ \\
\hline
\end{tabular}

Notes: Gyn drugs: drugs known to be associated with gynecomastia development. ${ }^{2}$ Adjusted for body mass index, smoking status, hypertension, hyperlipidemia, cardiovascular disease, cancer, alcohol-related disorders, and benign prostatic hyperplasia, conditional on the matching factors.

Abbreviations: 5ARI, 5-alpha reductase inhibitor; $\mathrm{AB}$, alpha blocker; adj OR, adjusted odds ratio; ref, reference; $\mathrm{Cl}$, confidence interval.

with luteinizing hormone-releasing hormone blockers were also null for ever users of 5ARIs compared to never users $(\mathrm{OR}=1.08,95 \%$ CI $0.62-1.87)$; the risk did not change with increased duration of 5ARI use. More recently, a cohort study using The Prescribed Drug Register in Sweden ${ }^{21}$ reported no increase in the risk of breast cancer for 5ARI or AB users compared to unexposed (5ARI hazard ratio $[\mathrm{HR}]=0.74$, 95\% CI 0.27-2.03; AB HR=1.47, 95\% CI 0.73-2.95) after a median 6 years of follow-up.

Strengths of our study included use of the CPRD, a large, validated, longitudinal primary care database known for high accuracy of diagnoses and completeness of drug 
Table 6 Breast cancer: characteristics of cases and controls

\begin{tabular}{|c|c|c|c|}
\hline Characteristics & $\begin{array}{l}\text { Breast } \\
\text { cancer cases, } \\
n=48, n(\%)\end{array}$ & $\begin{array}{l}\text { Controls, } \\
n=478, \\
n(\%)\end{array}$ & $\begin{array}{l}\text { Univariate OR } \\
(95 \% \mathrm{Cl})\end{array}$ \\
\hline \multicolumn{4}{|l|}{ Age (years) at index date } \\
\hline $40-49$ & $\mathrm{I}(2.1)$ & $10(2.1)$ & a \\
\hline $50-59$ & $4(8.3)$ & $42(8.8)$ & a \\
\hline $60-69$ & $8(16.7)$ & $88(18.4)$ & a \\
\hline $70-79$ & $20(41.7)$ & $198(4 \mid .4)$ & a \\
\hline $80-89$ & $15(31.3)$ & $140(29.3)$ & a \\
\hline Mean \pm SD & $73.2 \pm 9.9$ & $73.1 \pm 9.9$ & a \\
\hline \multicolumn{4}{|l|}{ Index year } \\
\hline$<1995$ & $\mathrm{I}(2.1)$ & $10(2.1)$ & a \\
\hline $1995-1999$ & $8(16.7)$ & $80(16.7)$ & a \\
\hline $2000-2004$ & $13(27.1)$ & $128(26.8)$ & a \\
\hline 2005-2009 & $14(29.2)$ & $140(29.3)$ & a \\
\hline$\geq 2010$ & $12(25.0)$ & $120(25.1)$ & a \\
\hline \multicolumn{4}{|c|}{ Length of record before index date (years) } \\
\hline Mean \pm SD & $11.2 \pm 5.9$ & $11.3 \pm 5.8$ & a \\
\hline \multicolumn{4}{|l|}{ BMI $\left(\mathrm{kg} / \mathrm{m}^{2}\right)$} \\
\hline$<18.5$ & I (2.I) & $9(1.9)$ & $1.02(0.12-8.56)$ \\
\hline $18.5-24.9$ & $15(31.3)$ & $145(30.3)$ & 1.0 (ref) \\
\hline $25-29.9$ & $25(52.1)$ & $219(45.8)$ & $1.10(0.56-2.16)$ \\
\hline$\geq 30$ & $7(14.6)$ & $85(17.8)$ & $0.8 \mathrm{I}(0.3 \mathrm{I}-2.08)$ \\
\hline Unknown & $0(0.0)$ & $20(4.2)$ & b \\
\hline \multicolumn{4}{|l|}{ Smoking status } \\
\hline Nonsmoker & $18(37.5)$ & $192(40.2)$ & 1.0 (ref) \\
\hline Smoker & $5(10.4)$ & $59(12.3)$ & $0.91(0.32-2.56)$ \\
\hline Ex-smoker & $3(6.3)$ & $32(6.7)$ & $1.25(0.62-2.49)$ \\
\hline Unknown & $22(45.8)$ & $195(40.8)$ & $0.95(0.25-3.57)$ \\
\hline \multicolumn{4}{|l|}{ Comorbidities } \\
\hline Hypertension & $16(33.3)$ & $174(36.4)$ & $0.86(0.44-1.68)$ \\
\hline Diabetes & $3(6.3)$ & $66(13.8)$ & $0.42(0.13-1.39)$ \\
\hline Hyperlipidemia & $6(12.5)$ & $83(17.4)$ & $0.65(0.26-1.66)$ \\
\hline Cardiovascular disease & $16(33.3)$ & $165(34.5)$ & $0.95(0.49-1.82)$ \\
\hline $\begin{array}{l}\text { Benign prostatic } \\
\text { hyperplasia }\end{array}$ & $22(45.8)$ & $211(44.1)$ & $1.09(0.57-2.09)$ \\
\hline $\begin{array}{l}\text { Gynecomastia } \\
\text { (diagnosed more than } \\
2 \text { years before index } \\
\text { date) }\end{array}$ & $3(6.3)$ & $4(0.8)$ & $\mathrm{b}$ \\
\hline $\begin{array}{l}\text { Alcohol-related } \\
\text { disorders }\end{array}$ & I (2.I) & $16(3.4)$ & $0.60(0.08-4.84)$ \\
\hline Prostate surgery & $8(16.7)$ & $33(6.9)$ & $3.07(1.23-7.63)$ \\
\hline
\end{tabular}

Notes: a Matching variable. 'Too few cases or controls.

Abbreviations: $\mathrm{OR}$, odds ratio; $\mathrm{BMI}$, body mass index; $\mathrm{Cl}$, confidence interval; $\mathrm{SD}$, standard deviation; ref, reference.

prescribing data. All information in the CPRD is recorded in the absence of a study hypothesis; therefore, there is no risk of recall bias. Our study results found known risk factors to be independently associated with gynecomastia and breast cancer, providing confidence in the quality of the data. In addition to 5ARIs, we also evaluated an alternative treatment of $\mathrm{BPH}$ and found that there was no increase in the risk of gynecomastia in users of $\mathrm{ABs}$ in comparison to unexposed men, whereas there was a threefold elevation in risk for users of 5ARIs compared to unexposed men. The inclusion of $\mathrm{ABs}$ as an active comparator provides reassurance that the elevation in risk observed in users of 5ARIs is not the result of confounding by indication. We further controlled our analyses for a range of potential confounders. By excluding men who had insufficient history in their medical record before cohort entry, we reduced the risk of including men who had prior exposure to a study drug before cohort entry, or with prevalent, rather than incident, gynecomastia, or breast cancer. Finally, the initial population of men prescribed 5ARIs and ABs for BPH $(n=94,701)$ was very robust, allowing us to evaluate the role of effect modification in the association between 5ARI use and risk of gynecomastia while still retaining adequate power. This is not possible in clinical trials given their smaller size. To date, the majority of information on the use of 5ARIs and the risk of gynecomastia has been derived from clinical trial adverse event reporting; thus, this study represents the first large, observational study of real-world data to evaluate this association.

There are some limitations to consider. We may have missed some gynecomastia or breast cancer cases; however, in the case-control analyses, missing cases should not impact estimates as it is not necessary to include all cases. Gynecomastia has been documented in clinical trials as an adverse event associated with the use of 5ARIs; therefore, men prescribed 5ARIs may have been more likely than men treated with $\mathrm{ABs}$ or unexposed men to be screened and diagnosed with gynecomastia (detection bias). If true, our results may overestimate the true effect of 5ARIs. However, the sensitivity analysis restricted to gynecomastia cases with supporting clinical codes produced similar results to the full analysis $(\mathrm{OR}=3.03$ vs $\mathrm{OR}=3.31)$. In addition, there was a greater than fivefold increase in risk of gynecomastia in users of 5ARIs, regardless of whether or not they received other prescription drugs known to be associated with gynecomastia, whereas we observed a 2.5 times greater risk of gynecomastia among the stratum of unexposed men and $\mathrm{AB}$ users with concomitant prescriptions for drugs known to be associated with gynecomastia. This suggests that detection bias does not explain our findings of increased risk of gynecomastia with the use of 5ARIs. Finally, our study population was composed of men with a diagnosis of BPH in the UK. Results from clinical trials conducted in many non-UK countries, which evaluated the efficacy of 5ARIs for the treatment of alopecia or the prevention of prostate cancer, have also reported increased rates of gynecomastia with the use of 5ARIs compared to placebo, ${ }^{18}$ suggesting that the increased risk of gynecomastia is independent of indication for 5ARI use and unlikely to be sensitive to variation in $\mathrm{BPH}$ diagnosis across different 
Table 7 Breast cancer case-control study: 5ARI and AB exposure among breast cancer cases and matched controls

\begin{tabular}{|c|c|c|c|c|}
\hline Exposure & $\begin{array}{l}\text { Breast cancer cases, } \\
n=48, n(\%)\end{array}$ & $\begin{array}{l}\text { Controls, } n=478 \text {, } \\
n(\%)\end{array}$ & Crude OR $(95 \% \mathrm{Cl})$ & $\operatorname{Adj~OR~}^{a}(95 \% \mathrm{Cl})$ \\
\hline \multicolumn{5}{|l|}{ Ever prescribed } \\
\hline Nonexposed & $27(56.3)$ & $278(58.2)$ & 1.0 (ref) & 1.0 (ref) \\
\hline $5 A R I$ (alone or in combination with $A B$ ) & $10(20.8)$ & $58(12 . I)$ & $1.86(0.79-4.37)$ & $1.52(0.61-3.80)$ \\
\hline$A B$ only & II (22.9) & $142(29.7)$ & $0.82(0.37-1.82)$ & $0.71(0.31-1.62)$ \\
\hline \multicolumn{5}{|l|}{ Combination ever prescribed } \\
\hline Nonexposed & $27(56.3)$ & $278(58.2)$ & 1.0 (ref) & 1.0 (ref) \\
\hline 5ARI only & $2(4.2)$ & $15(3.1)$ & b & $\mathrm{b}$ \\
\hline $5 A R I$ and $A B$ & $8(16.7)$ & $43(9.0)$ & $1.97(0.79-4.89)$ & $1.65(0.63-4.34)$ \\
\hline$A B$ only & II (22.9) & $142(29.7)$ & $0.82(0.37-1.82)$ & $0.71(0.31-1.62)$ \\
\hline \multicolumn{5}{|l|}{ Number of prescriptions } \\
\hline Nonexposed & $27(56.3)$ & $278(58.2)$ & 1.0 (ref) & 1.0 (ref) \\
\hline $\begin{array}{l}5 \mathrm{ARI} \text { (alone or in combination with } \mathrm{AB} \text { ), } \\
<10 \text { prescriptions }\end{array}$ & $6(12.5)$ & $22(4.6)$ & $2.89(1.03-8.12)$ & $2.27(0.76-6.77)$ \\
\hline $\begin{array}{l}5 A R I \text { (alone or in combination with } A B \text { ), } \\
\geq 10 \text { prescriptions }\end{array}$ & $4(8.3)$ & $36(7.5)$ & b & b \\
\hline$A B$ only, $<10$ prescriptions & $2(4.1)$ & $53(1 \mathrm{I} .1)$ & b & $\mathrm{b}$ \\
\hline$A B$ only, $\geq 10$ prescriptions & $9(18.8)$ & $89(18.6)$ & $1.07(0.45-2.55)$ & $0.99(0.4 \mathrm{I}-2.39)$ \\
\hline
\end{tabular}

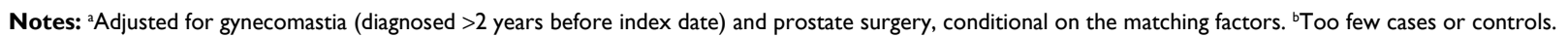

Abbreviations: 5ARI, 5-alpha reductase inhibitor; AB, alpha blockers; adj OR, adjusted odds ratio; $\mathrm{Cl}$, confidence interval; SD, standard deviation; ref, reference.

countries. Therefore, these results should be generalizable to men with $\mathrm{BPH}$ outside the UK.

\section{Conclusion}

In a large, UK population-based electronic medical record database, the risk of gynecomastia was three times higher in men aged $\geq 40$ years who used 5ARIs for the treatment of BPH compared to nonusers. These results are similar to previous studies that reported an increased risk of gynecomastia with the use of 5ARIs. In contrast, where prior case reports have raised concern about breast cancer with the use of 5ARIs, our results suggest that there is no increased risk of breast cancer among men using 5ARIs in comparison to unexposed men.

\section{Acknowledgments}

Hozefa A. Divan and Shona C. Fang were employees of New England Resarch Institute during this study; however, both have changed affiliations before publication. Divan is now affiliated with Therapeutics Research and Infections Disease Epidemiology Group, Department of Population Medicine, Harvard Medical School and Harvard Pilgrim Health Care Institute. Fang is now affiliated with Alexion Pharmaceuticals, Lexington, MA, USA. All authors have support from the United States National Institutes of Health/National Institute of Diabetes and Digestive and Kidney Diseases grant (5R21DK100820-02) for the submitted work. These sponsors did not have any role in the design/conduct of the study, collection/management of the data, analysis, interpretation of the data, or preparation, review, or approval of the manuscript.

\section{Author contributions}

All authors contributed toward data analysis, drafting, and revising the paper and agree to be accountable for all aspects of the work.

\section{Disclosure}

Katrina Wilcox Hagberg certifies that all conflicts of interest, including specific financial interests and relationships and affiliations relevant to the subject matter or materials discussed in the manuscript (e.g., employment/affiliation, grants or funding, consultancies, honoraria, stock ownership or options, expert testimony, royalties, or patents filed, received, or pending), are the following: all authors have support from the United States National Institutes of Health/ National Institute of Diabetes and Digestive and Kidney Diseases grant (5R21DK100820-02) for the submitted work. Katrina Wilcox Hagberg, Hozefa A. Divan, Shona C. Fang, and Susan S. Jick have no relationships that might have an interest in the submitted work. J. Curtis Nickel had a financial relationship with GlaxoSmith Kline 3 years ago consulting on a nonrelated patent lawsuit and has a current nonfinancial relationship with GlaxoSmithKline for access to REDUCE trial data for research outside of the submitted work. None of the authors have nonfinancial interests that may be relevant to the submitted work. The authors report no other conflicts of interest in this work.

\section{References}

1. Carlin BI, Seftel AD, Resnick MI, Findlay J. Finasteride induced gynecomastia. J Urol. 1997;158(2):547. 
2. Wilton L, Pearce G, Edet E, Freemantle S, Stephens MD, Mann RD. The safety of finasteride used in benign prostatic hypertrophy: a noninterventional observational cohort study in 14,772 patients. Br J Urol. 1996;78(3):379-384.

3. Schulman C, Pommerville P, Höfner K, Wachs B. Long-term therapy with the dual 5alpha-reductase inhibitor dutasteride is well tolerated in men with symptomatic benign prostatic hyperplasia. BJU Int. 2006; 97(1):73-79.

4. Corona G, Rastrelli G, Maseroli E, et al. Inhibitors of $5 \alpha$-reductaserelated side effects in patients seeking medical care for sexual dysfunction. J Endocrinol Invest. 2012;35(10):915-920.

5. Desgrandchamps F, Droupy S, Irani J, Saussine C, Comenducci A. Effect of dutasteride on the symptoms of benign prostatic hyperplasia, and patient quality of life and discomfort, in clinical practice. BJU Int 2006;98(1):83-88.

6. Narula HS, Carlson HE. Gynaecomastia-pathophysiology, diagnosis and treatment. Nat Rev Endocrinol. 2014;10(11):684-698.

7. Deepinder F, Braunstein GD. Drug-induced gynecomastia: an evidencebased review. Expert Opin Drug Saf. 2012;11(5):779-795.

8. Miao H, Verkooijen HM, Chia KS, et al. Incidence and outcome of male breast cancer: an international population-based study. J Clin Oncol. 2011;29(33):4381-4386.

9. Medicines and Healthcare products Regulatory Agency. Finasteride: potential risk of male breast cancer; 2009. Available from: https://www gov.uk/drug-safety-update/finasteride-potential-risk-of-male-breastcancer. Accessed November 1, 2014.

10. U.S. Food and Drug Administration. Potential Signals of Serious Risks/ New Safety Information Identified by the Adverse Event Reporting System (AERS) October-December 2009; 2010. Available from: http:// www.fda.gov/Drugs/GuidanceComplianceRegulatoryInformation/ Surveillance/AdverseDrugEffects/ucm210293. Accessed November $1,2014$.
11. Lawson DH, Sherman V, Hollowell J. The general practice research database. Scientific and Ethical Advisory Group. QJM. 1998;91:445-452.

12. Herrett E, Gallagher AM, Bhaskaran K, et al. Data resource profile: clinical practice research datalink (CPRD). Int J Epidemiol. 2015; 44(3):827-836.

13. Jick SS, Kaye JA, Vasilakis-Scaramozza C, et al. Validity of the general practice research database. Pharmacotherapy. 2003;23(5):686-689.

14. Thompson IM, Goodman PJ, Tangen CM, et al. The influence of finasteride on the development of prostate cancer. $N$ Engl J Med. 2003; 349(3):215-224

15. Andriole GL, Bostwick DG, Brawley OW, et al. Effect of dutasteride on the risk of prostate cancer. N Engl J Med. 2010;362:1192-1202.

16. Roehrborn CG, Boyle P, Nickel JC, et al. Efficacy and safety of dual inhibitor 5-alpha-reductase types 1 and 2 (dutasteride) in men with benign prostatic hyperplasia. Urology. 2002;60(3):434-441.

17. Kaplan SA, Chung DE, Lee RK, Scofield S, Te AE. A 5-year retrospective analysis of $5 \alpha$-reductase inhibitors in men with benign prostatic hyperplasia: finasteride has comparable urinary symptom efficacy and prostate volume reduction, but less sexual side effects and breast complications than dutasteride. Int J Clin Pract. 2012;66(11): 1052-1055.

18. Trost L, Saitz TR, Hellstrom WJG. Side effects of 5-alpha reductase inhibitors: a comprehensive review. Sex Med Rev. 2013;1:24-41.

19. Bird ST, Brophy JM, Hartzema AG, Delaney JA, Etminan M. Male breast cancer and $5 \alpha$-reductase inhibitors finasteride and dutasteride. J Urol. 2013;190(5):1811-1814.

20. Duijnhoven RG, Straus SM, Souverein PC, et al. Long-term use of $5 \alpha$-reductase inhibitors and the risk of male breast cancer. Cancer Causes Control. 2014;25:1577-1582.

21. Robinson D, Garmo H, Holmberg L, Stattin P. 5- $\alpha$ Reductase inhibitors, benign prostatic hyperplasia, and risk of male breast cancer. Cancer Causes Control. 2015;26(9):1289-1297.
Clinical Epidemiology

\section{Publish your work in this journal}

Clinical Epidemiology is an international, peer-reviewed, open access, online journal focusing on disease and drug epidemiology, identification of risk factors and screening procedures to develop optimal preventative initiatives and programs. Specific topics include: diagnosis, prognosis, treatment, screening, prevention, risk factor modification,

Submit your manuscript here: https://www.dovepress.com/clinical-epidemiology-journal

\section{Dovepress}

systematic reviews, risk and safety of medical interventions, epidemiology and biostatistical methods, and evaluation of guidelines, translational medicine, health policies and economic evaluations. The manuscript management system is completely online and includes a very quick and fair peer-review system, which is all easy to use. 